Document downloaded from:

http://hdl.handle.net/10251/81386

This paper must be cited as:

Nácher-Soler, VE.; García Sanjuan, F.; Jaén Martínez, FJ. (2016). Interactive technologies for preschool game-based instruction: Experiences and future challenges. Entertainment Computing. 17:19-29. doi:10.1016/j.entcom.2016.07.001.

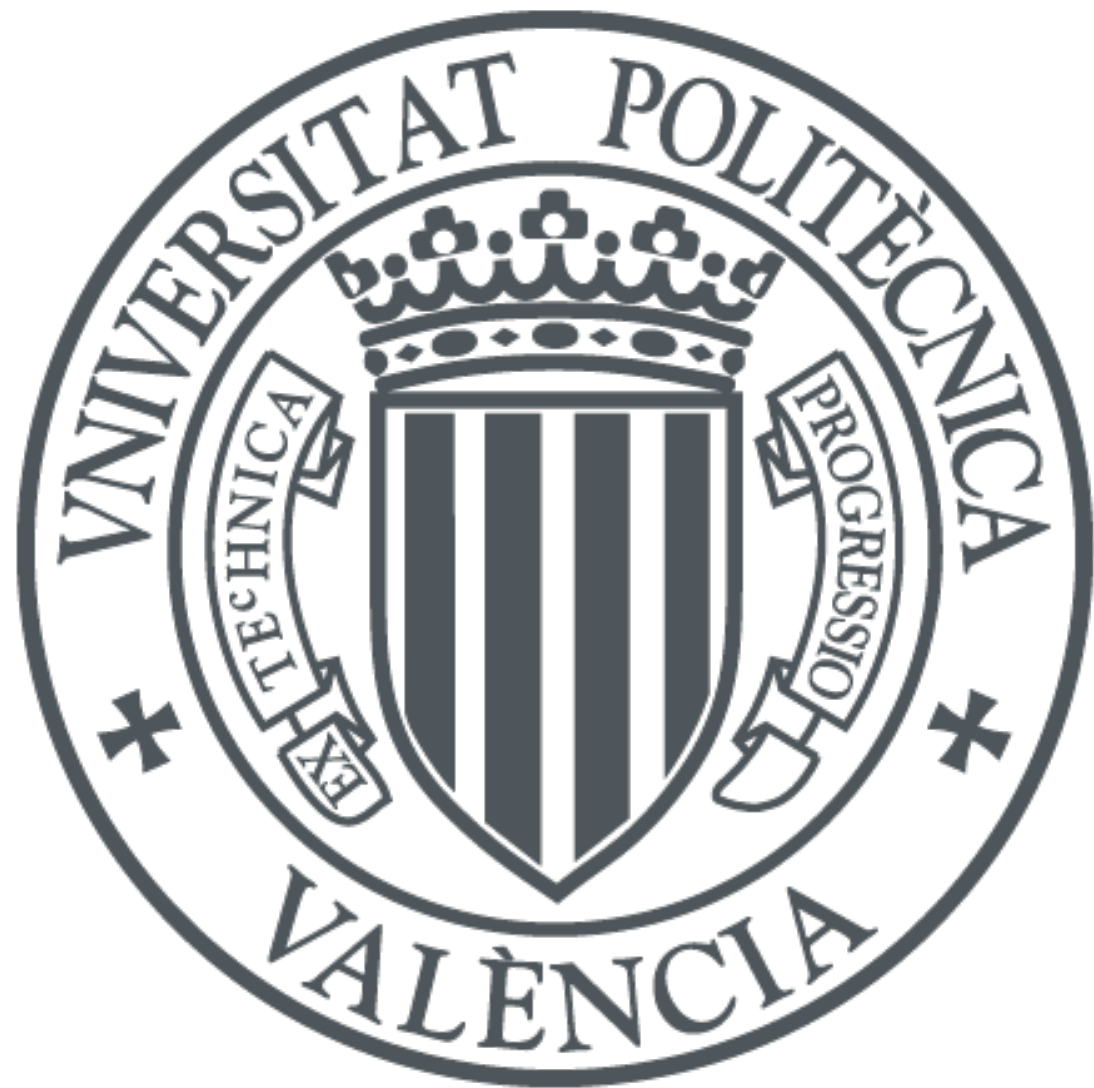

The final publication is available at

http://dx.doi.org/10.1016/j.entcom.2016.07.001

Copyright Elsevier

Additional Information

this is the author's version of a work that was accepted for publication in Entertainment Computing. Changes resulting from the publishing process, such as peer review, editing, corrections, structural formatting, and other quality control mechanisms may not be reflected in this document. Changes may have been made to this work since it was submitted for publication. A definitive version was subsequently published in Entertainment Computing, vol. 17 (2016). DOI 10.1016/j.entcom.2016.07.001. 


\title{
Interactive Technologies for Preschool Game-Based Instruction: Experiences and Future Challenges
}

\author{
Vicente Nacher ${ }^{1}$ \\ ISSI Group, Departamento de Sistemas Informáticos y Computación (DSIC), Universitat Politècnica de València \\ Camino de Vera s/n. 46022 Valencia (Spain) \\ vnacher@dsic.upv.es \\ Fernando Garcia-Sanjuan \\ ISSI Group, Departamento de Sistemas Informáticos y Computación (DSIC), Universitat Politècnica de València \\ Camino de Vera s/n. 46022 Valencia (Spain) \\ fegarcia@dsic.upv.es \\ Javier Jaen \\ ISSI Group, Departamento de Sistemas Informáticos y Computación (DSIC), Universitat Politècnica de València \\ Camino de Vera s/n. 46022 Valencia (Spain) \\ tel +3496387 7007, fax +3496387 7359 \\ fjaen@upv.es
}

\footnotetext{
${ }^{1}$ Corresponding author
} 


\title{
Interactive Technologies for Preschool Game-Based Instruction: Experiences and Future Challenges
}

\begin{abstract}
According to current kindergarten curricula, game play is an important basis for children development and it is the main driving force when designing educational activities during early childhood. This paper presents a review of the current state of the art of game technologies that support pre-kindergarten and kindergarten children development. Moreover, the most emergent technologies for developing educational games for preschool children are identified and a set of future challenges are discussed. The main goal of this work is to define a path of future research for educators, game designers and Human-Computer Interaction (HCI) experts in the area of game-based kindergarten instruction.
\end{abstract}

\section{Keywords}

Games, Kindergarten, Education, Serious games, Multi-touch, Robots

\section{Introduction}

According to Huizinga, play is innate to human culture [1] and children play in many ways and with different types of artifacts [2]. The importance and benefits of game play in early childhood education and development are manifold as discussed by Singer et al. [3] who studied how play motivates and enhances children's cognitive and social-emotional growth, and by Ginsburg [4] who pointed out that play is essential for development contributing to the cognitive, physical, social and emotional well-being. Consequently, play should be a basic pillar in children education and development as pointed out by Plato [5]: "Enforced learning will not stay in mind. So avoid compulsion and let your children's lessons take the form of play".

However, despite the large number of works addressing children play (e.g., $[6,7,8,9,10,11])$ and the presence of games in children educational curricula, considerable less research has focused on the relationship between play, learning and technology in the context of early childhood education. In this respect, traditional desktop computers have often been considered as the main technological devices to be used, leaving new emerging technologies such as interactive surfaces and robots, which could be exploited to obtain richer game experiences, underused. 
Therefore, in this paper we provide a review of works that use technologies to develop games to help preschool children improve the three dimensions of their development mentioned above: physical, socio-affective and intellectual. The analysis carried out shows that despite there are technologies with suitable mechanisms to support very young children instruction based on play, there are still missing aspects that need to be addressed in order to fully support these dimensions in children's development. Hence, we provide a set of future areas of work that can be addressed in the near future. The end goal is to define a research path to give educators and designers appropriate guidelines to design game activities using each technology and to devise games and educational activities that smoothly combine all the evaluated technologies creating environments that foster preschool children's development.

\section{Technology-Supported Games for Preschool Children}

In the literature, many previous works using technology-aided learning activities to support preschool children (aged 2-6 years) development can be found. In this section, these works are explored and classified by the main technological components they rely on, namely traditional computers, interactive surfaces and also robots and other technologically-enhanced toys. Their different interaction mechanisms are discussed, as well as the affordances they present and their potential to design games that stimulate preschooler's physical, socio-affective and intellectual abilities.

\subsection{Traditional Computers}

In the past two decades, the main strand when developing intellectual and cognitive abilities among kindergarten children through technology was the use of traditional computers, which were mainly interacted via mouse and keyboard. Since regular keyboards have too many keys and can cause difficulties for very young children to interact with, some approaches required either disabling or removing some keys in order to simplify interactions. Jones and Liu [12], for instance, evaluated how 2 to 3 year-old children interact with a computer. For this purpose, they designed a videogame which used visual stimuli, animations and audio to capture the kid's attention. The computer told the child to press a certain keyboard button, and informed the user whether the interaction had been successful. Simplification was achieved in this case by using only a few keys of the keyboard, disabling the rest. The game contained educative contents in order to enhance vocabulary through learning colors, toy names, food, computer parts, etc., and also to learn mathematical concepts such as big/small, or logical relations like cause/effect (e.g., if a key is pressed, something will happen on the screen). In their study, the researchers observed that meaningful interactions with this kind of technology do not appear before 2.5 years of age, but perhaps their findings were biased by having too many keys presented to the participants, even though not all of them were responsive. Another example is the work by van 
Daal and Reitsma [13] which evaluated a computer assisted program for learning to read and spell. The program includes several exercises such as matching pictures with spoken words, indicating which letter sound is heard and matching written words with pictures and spelling a word by its sound (see Figure 1). The results showed that the children who used the computerbased reading and spelling activities learned to name more letters and they were able to read more words than the group of children who did not have access to the computer-based practice. Hence, the proposed approach helped children in the improvement of their recognition and decoding skills.

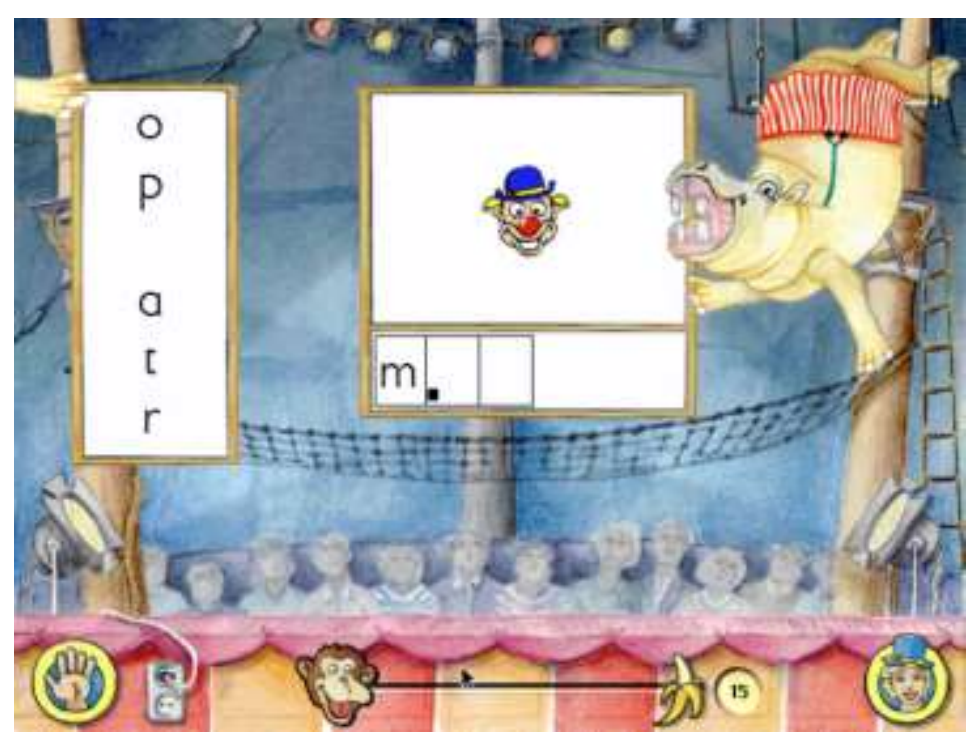

Figure 1. Example screen of the activity spelling a word by its sound (from [13]).

Instead, other works get rid of keyboards completely and replace them by other intrinsically simpler devices. This is the case of Strommen et al. [14], who designed a videogame that consisted on directing a Cookie Monster through a path up to a given target cookie for him to eat. They designed the game to be controlled by a mouse, joystick or trackball, and performed an evaluation to assess which input device improved precision tasks on 3-year-olds. The results showed the trackball was the more accurate, but the slowest, way to interact. Similarly, Ahlström and Hitz [15] evaluated precise pointing interactions using mouse on children aged 48-58 months. In order to do so, they proposed a game that consisted on selecting and dragging colored elements on the screen. Results showed that an assistive technique can improve children's pointing accuracy. Navarro-Newball et al. [16] reduced the complexity of the interaction even further. They shied away from an interaction mediated by keyboard and mouse and designed a videogame which required speech interaction and gave visual feedback to children. The game, Talking to Teo, was aimed at the rehabilitation of children with early diagnosed hearing impairment. During the experiments carried out with a therapist it was evidenced that the game resulted enjoyable and engaging for children when performing a task usually boring for them such as repetitive speech mechanization sessions. 
Despite devising easier interaction mechanisms for children, scenarios with this type of technology are mainly mono-user, where, if several users are present in front of a computer, one tends to retain the control whereas the rest adopt a more passive (observer) role. This could complicate the design of games to foster social abilities. Besides, experiences are limited to happen in front of the computer, because these are fixed to a single location. Therefore, it would be difficult for kids to engage in games that encouraged mobility and physical exercise using this kind of technologies. However, other types of physical development, such as the improvement of fine motor skills, could be trained using traditional computers. As an example, the Cookie Monster game by Strommen et al. [14] and the drag game by Ahlström and Hitz [15] require precision in order to succeed. Even though these two works were not aimed at training any specific capacity, in our opinion, videogames that require this type of precision could be used to improve fine motor skills on children.

\subsection{Interactive Surfaces}

The natural and intuitive way of interaction provided by the multi-touch technology [17] makes it ideal for preschool children. The three basic ideas behind the direct manipulation style that enables a natural interaction are stated by Shneiderman et al. [18]: the first one is the visibility of objects and actions of interest; the second one, the replacement of typed commands by pointing-actions on the objects of interest; and, finally, the rapid, reversible and incremental actions help children to keep engaged and give them control over the technology avoiding complex instructions that complicate the interaction. In recent years, several studies have focused on the use of multi-touch interactive tabletops with educational purposes, not only because of the naturalness of the interactions but also because they allow co-located experiences where social skills such as collaboration can be fostered. For example, Kammer et al. [19] presented three applications to foster the development of cognitive and motor skills on a tabletop with children aged 4 to 6 years. The experiment conducted showed that preschool children were able to use this technology and they enjoyed the task and collaborated in the multi-user activity. Tyng et al. [20] developed a set of applications for teaching preschool mathematics also based on a multi-touch tabletop (see Figure 2-a). Their results showed that despite the difficulty of children understanding the concepts of addition and subtraction operations, the platform helped children learn them and the interactive environment facilitated collaboration and engagement. Another interesting example is the work of Mansor et al. [21] who conducted a comparison of a physical setting versus a collaborative multi-touch tabletop setting with children aged between 3 and 4 years and suggested that kids should remain standing during these operations because, otherwise, they would find it difficult to drag objects on the surface due to bad postures. Finally, Huber et al. [22] evaluated the transfer of learning from a touchscreen device to the real world in children aged 4 to 6 years. The kids performed two 
tasks: first they learned how to solve a problem, consisting on solving a Tower of Hanoi, using a touchscreen device; then, they had to solve the same problem with physical objects. The results showed that children got significant improvements from the practice irrespective of the type of manipulation performed (physical objects vs touchscreen device). Hence, the authors concluded that children's learning on the touchscreen device was appropriately transferred to the physical version.

Multi-touch interaction on digital tabletops can be extended with the use of tangibles, which provide a more natural and intuitive means of interaction. For example, Yu et al. [23] presented a set of applications for children aged between 5 and 6 years. These applications contributed to the development of intelligence and linguistic, logical, mathematical, musical and visual-spatial capabilities through activities such as listening to a word and picking out the picture that represented it, shooting balloons with the right numbers, etc. Following the same research path, Khandelwal \& Mazalek [24] presented the Teaching Table system based on a tabletop for basic mathematics learning for pre-kindergarten children (see Figure 2-b). This work showed that children aged between 3 and 6 years were engaged with the platform and it allowed collaborative actions when learning through play. Further, Sluis et al. [25] designed Read-It, a multi-modal, tangible and collaborative tabletop application that was shown to effectively support children aged 5 to 7 to read.

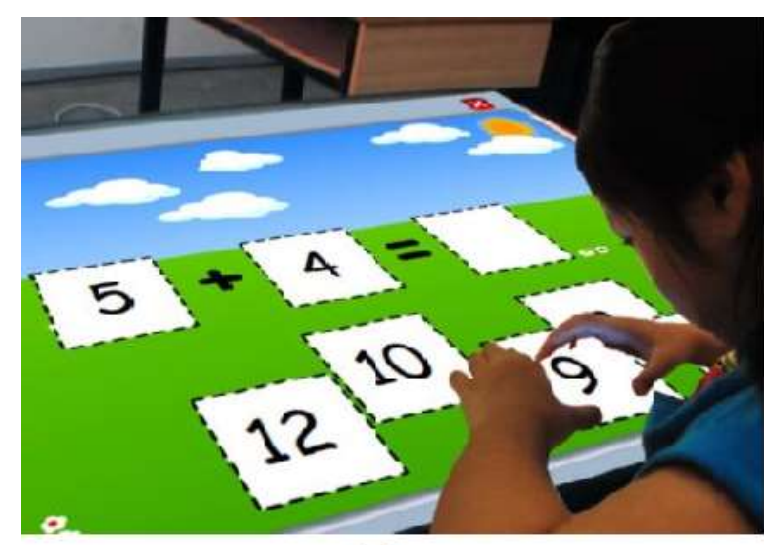

(a)

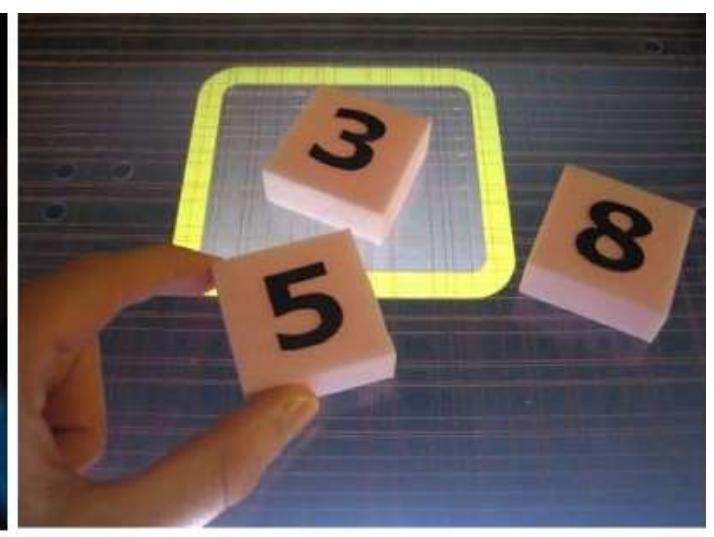

(b)

Figure 2. (a) MEL-Vis from [20]. (b) The Teaching Table from [24].

Finally, Marco et al. [26,27] designed the Farm Game (see Figure 3); a virtual farm with a farmer as a virtual agent shown on the screen. The interaction is carried out by manipulating physical toys over the table surface and a visual recognition software translates the real condition into a $3 \mathrm{D}$ virtual environment shown on a TV. The authors pointed out that the platform could be used to implement a storytelling game and, additionally, adding more complex behavior with emotional content could help to a richer playing experience. 


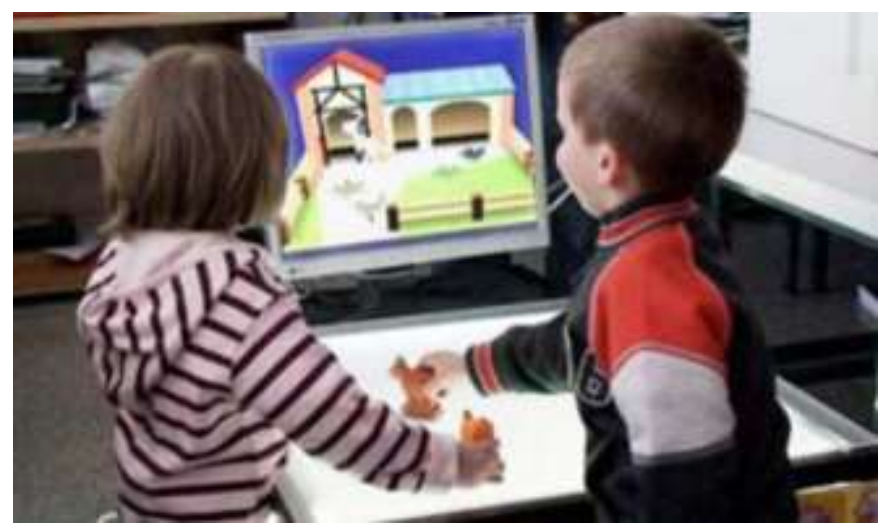

Figure 3. Children playing in the The Farm Game [26,27].

In a similar way to computers, one drawback of tabletops is their reduced mobility, hence not being very suitable to design games that might involve physical exercise. Recent research [28] [29] has shown that tablets and smartphones, which are nearly of common use nowadays, can be placed together on a flat surface and form a multi-display environment that resembles a tabletop. Therefore, multiple children can engage together in the same game in a co-located way where social skills can be developed and these handheld devices can also be moved in order to add physical mobility to the games.

Many sources have praised the suitability of tablets and smartphones for being used in education with very young children, In this respect, the Horizon report [30] placed them as emerging technologies suitable for children aged under 2 years, and Hirsh-Pasek et al. [31] pointed out that the most popular category in the Apple App Store is the "educational" category made of more than 80,000 applications. Indeed, several studies have recently delved into using tablets and smartphones in preschool instruction. Zaranis et al. [32] conducted an experiment to evaluate the effectiveness of digital activities on smart mobile devices (tablets) when teaching mathematical concepts to kindergarten children such as general knowledge of numbers, efficient counting, sorting and matching. Their results confirmed that the tablet-aided learning provided better learning outcomes than the traditional (non-technological) teaching method. Another study conducted by Chiong and Shuler [33] involved audiovisual material on touch devices adapted to children aged 3 to 7 years and their results showed that children obtained remarkable gains in vocabulary and phonological awareness. Another work using tablets is the study by Berggren and Hedler [34] in which the authors presented CamQuest, a tablet application that enables children to move around and recognize geometric shapes in the real objects that they see. The tablet shows the images from the camera and the application integrates the geometric shape to look for (see Figure 4). This application combines the learning of shapes (such as circle, square, rectangle and triangle) with active play since children are investigating their surroundings. Moreover, the application can be used in pairs therefore fostering collaboration, and enables defining roles between participants, so that children develop their social skills. 


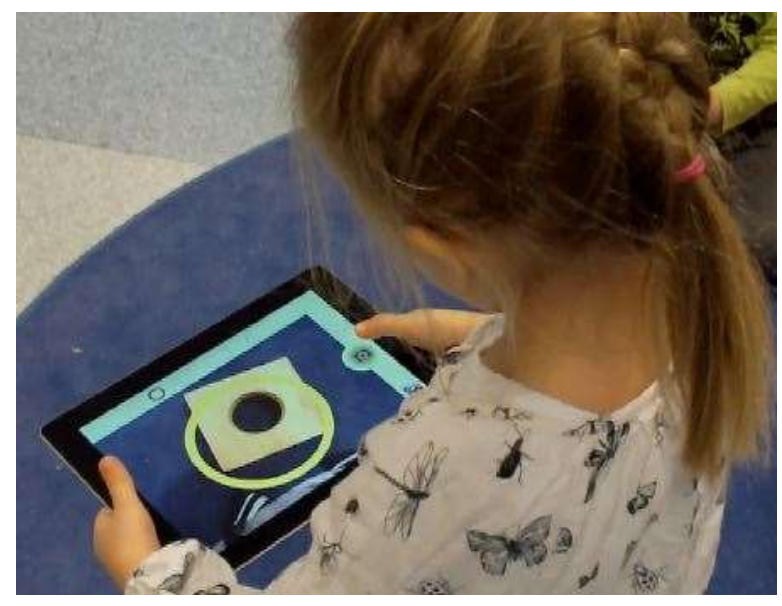

Figure 4. Child interacting with CamQuest (extracted from [34]).

Many other studies have focused on the feasibility of multi-touch interactions on these small devices for such group of users. For instance, the works by Nacher et al. [34, 35], not only reveals the huge growth in the number of existing educational applications targeted to prekindergarten children, but also evaluates a set of basic multi-touch gestures (tap, double tap, long pressed tap, drag, scale up, scale down, one finger rotation and two finger rotation) in a tablet with children aged between 2 and 3. Their results showed that pre-kindergarten children are able to perform successfully the tap, drag, scale up, scale down and one-finger rotation gestures without assistance, as well as the long pressed and double tap gestures with some assistive techniques that fit the gesture to the actual abilities of children. Another interesting study was conducted by Vatavu et al. [37] who evaluated the tap, double tap, single hand drag and double hand drag gestures (see Figure 5) with children between 3 and 6 years with tablets and smartphones. Overall, their results showed good performance except for the double hand drag gestures, which were affected by some usability issues. Moreover, their results showed a correlation between children with higher visuospatial skills (i.e. having better skills for understanding relationships between objects, as location and directionality) and a better performance in the drag and drop tasks and the accuracy when performing tap gestures. The work by Nacher and Jaen [38] goes a step further and presents a usability study of touch gestures that imply movement of the fingers on the tablet (drag, scale up, scale down and one finger rotation) requiring high levels of accuracy in the termination phase of the gestures. Their results showed that very young children (from 2 to 3 years old) are able to perform these gestures but with significant differences between them in terms of precision depending on their age since they are in the process of developing their fine motor skills. Finally, the authors proposed as a future work an adaptive mechanism that fits the required accuracy to the actual level of development of each child. 

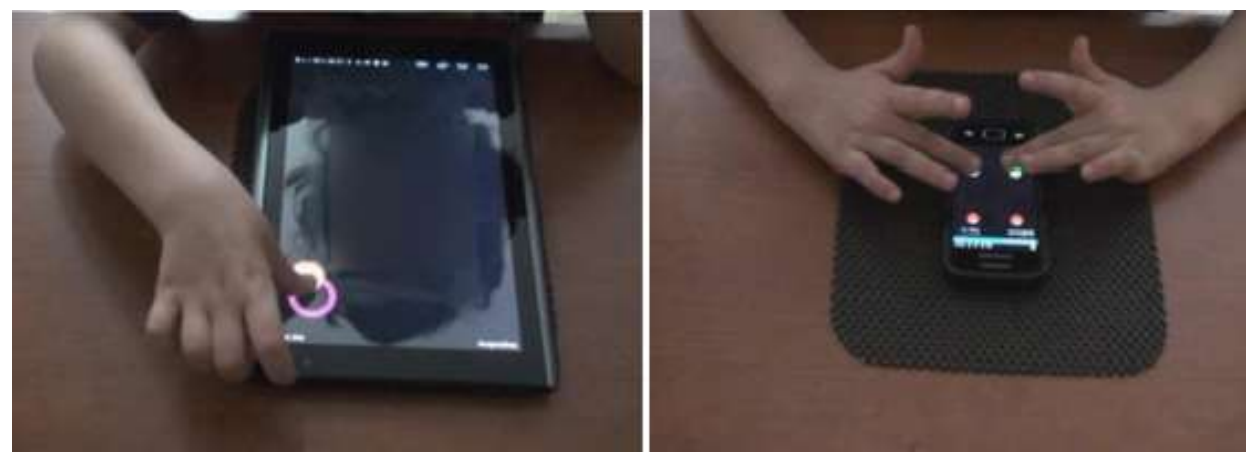

Figure 5. Child performing simple and double drag gestures (extracted from [37]).

Nacher et al. [39] also made a preliminary analysis of communicability of touch gestures comparing two visual semiotic languages (see Figure 6). The results showed that the animated approach had higher success rates and it overcame the iconic one. Hence, basic reasoning related to the interpretation of moving elements on a surface can be effectively performed during early childhood. The work by Hiniker et al. [40] evaluated different types of prompts for eliciting gestures such as double tap, horizontal and vertical swipe and shaking the tablet. They evaluated prompts such as in-app audio, on-screen demonstrations (with hand demos or changing the visual state of the item) and instructions by an adult model with children aged between 2 and 5 . Their results showed that despite the most effective one was the adult guidance, children aged 3 years or older were able to follow other types of cues. These languages or prompts could help children identify direct mappings between visual stimulus and their associated touch gestures. Therefore, the use of these languages could be particularly interesting in the development of games in which preschool children could play autonomously. Moreover, the use of these semiotics might help children in developing their symbolic thinking. Although the studies listed above developed their applications for experimental purposes, these or similar applications could be used as games in order to help children in their fine-motor and visuospatial skills development through interactive surfaces.

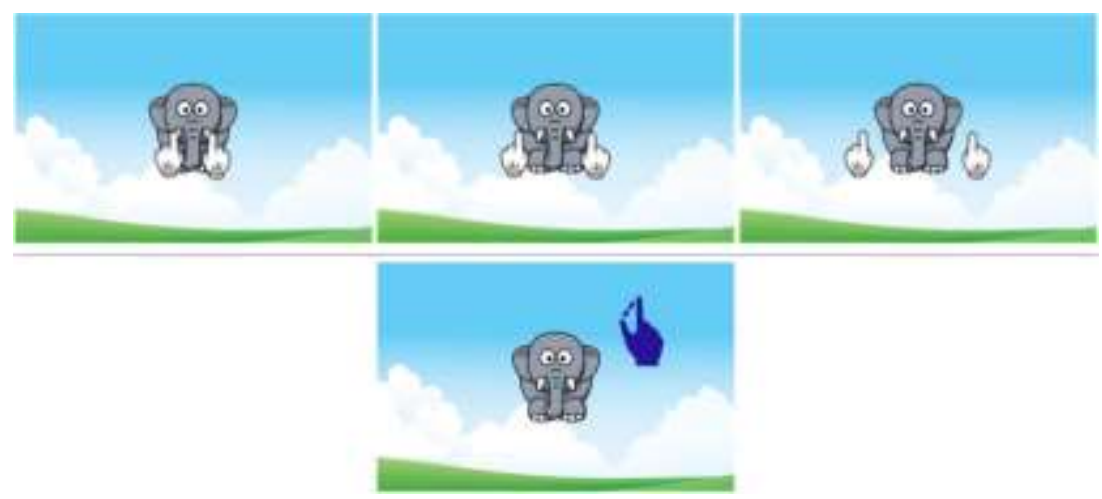

Figure 6. Description of the animated visual (top) and the iconic (bottom) language for the scale up gesture (extracted from [39]). 


\subsection{Robots and Technologically-Enhanced Toys}

Unlike computers or interactive surfaces, tridimensional toys and robots have the capacity of being grasped, hence serving as a sort of tangible user interface (TUI), which presents an added value in childhood education "as they resonate with traditional learning manipulatives" [41]. The research activities to design robots for (pre-)kindergarten children have focused on developing intellectual capacities such as linguistic aptitudes. In this respect, Ghosh and Tanaka [42] designed a Care-Receiving Robot (CRR) to give support in English learning to children aged between 3 and 6 years. Two games were proposed: a game to learn colors and another to learn vocabulary about animals. In the first one, called Color Project, the kids showed a colored ball to the robot and told it which color it was. Then, the robot touched the ball and guessed its color. In the second game, Vocabulary Project, a series of flashcards were shown to the robot, and it had to guess which animals they represented. The methodology used implied that children acted as teachers and the robot adopted the role of the pupil. In both games, the kid had to correct the robot when it was wrong, or to congratulate it when it answered correctly. The results of the experimentation with children revealed that they were very motivated at first, but tended to feel bored and frustrated quickly if the robot was too often right or wrong, respectively, because the game became monotonous. Tanaka and Matsuzoe [43] went further and revealed that kids aged 3 to 6 are capable of learning verbs by playing with the $C R R$, and they even suggested that learning through playing with the robot might be more effective than not involving such a tangible artifact. Soute and Nijmeijer [44] also designed a robot aiming to help in the language and literacy skills development. In this case, an owl-shaped robot (see Figure 7-a) to perform story-telling games with children aged 4 to 6 was designed. The robot narrated partial stories that children had to complete by showing flashcards to it. The small study session conducted showed that the system was engaging for the kids.

Shen et al. presented Beelight [45], a system composed of a bee-shaped robot and a tabletop serving as its honeycomb (see Figure 7-b), aimed at teaching colors to children aged 4 to 6 years. Two games were implemented with this approach. On the one hand, Color Sharing, in which the kids would grab the robot and show a color to it. Then, the bee would glow in said color and, if placed on the honeycomb, it would be colored as well. The second game, Color Searching, would consist of the bee being illuminated with a given color and the children having to search for some object of said color and place it on the honeycomb. In case of success, the honeycomb would play a song. After the experimentation, the authors reported that the platform caused excitement and astonishment on the kids. 


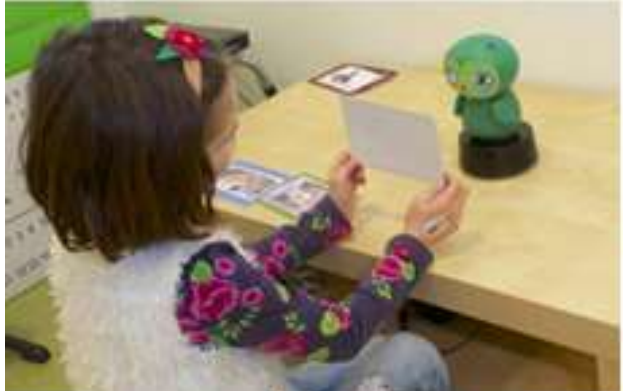

(a)

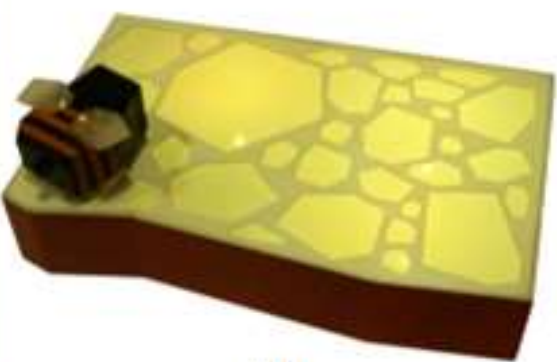

(b)

Figure 7. (a) Owl-shaped robot (extracted from [44]). (b) Beelight (extracted from [45]).

In addition to the use of robots for training intellectual abilities, they could also be used to develop spatial capabilities. For example, Tanaka and Takahashi [46] designed a tangible interface for kids aged 3 to 6 in the form of a tricycle (see Figure 8-a) to remotely control a robot. When children moved with the tricycle, the same movements (i.e., forward, backward, left, right) were mapped to movements of the tele-operated robot. Despite the robot not being designed with this purpose in mind, this type of interfaces could be used to stimulate spatial mappings and develop spatial sense on kindergarten children.

One of the main advantages of using robots is that they can move. Therefore, they could be used to enhance physical development. Exploiting this idea, Tanaka et al. [47] presented a humanoid robot called QRIO. QRIO was designed to be introduced in a toddlers' classroom to make the kids move and dance, hence encouraging physical exercise. The interaction with this robot was however limited since it would dance autonomously to the music (see Figure 8-b) and react to the movements of a dancing partner (i.e, to his/her hand movements or clapping).

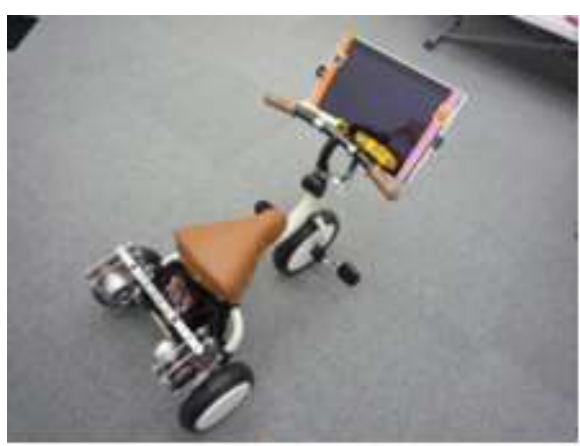

(a)

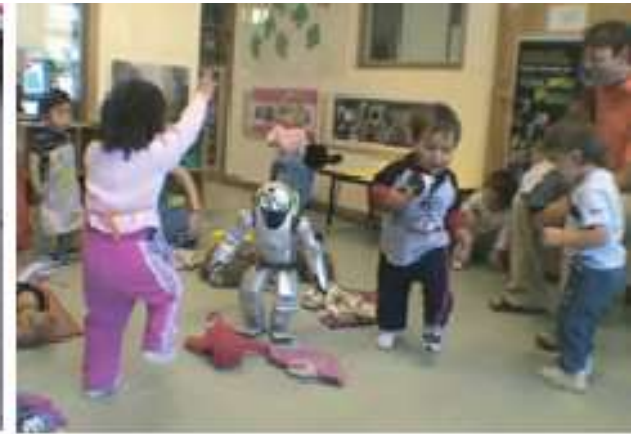

(b)

Figure 8. (a) Tricycle interface (extracted from [46]). (b) Children dancing with QRIO (extracted from [47])

Another interesting approach of an enhanced toy to foster physical exercise and the training of spatial abilities is shown in the work by Garcia-Sanjuan et al. [48]. In this case, the technological platform presented (see Figure 9) was aimed at supporting learning activities for pre-kindergarten children (up to 5 years) using a TUI-mediated mobile robot. Their results showed that the platform caused high excitement among children and most of the kids were able to drive the robot successfully. Therefore, the interaction proposed was proven simple and 
intuitive enough for these specific and special users that are kindergarteners. Additionally, in their work the authors pointed out possible educational activities identified by actual educators in which the robot could be involved. For example, it could be used to train some psychomotor skills by making the robot move, possibly reproducing a sound to attract the attention of the children, and stimulate them to follow it. Additionally, the platform could be useful when teaching concepts such as "move/stop", "forwards/backwards", "left/right" or "quick/slow". Other learning activities could be designed by using physical objects that represent concepts to be learned and by asking children to drive the robot until reaching the position of said physically-represented concept.

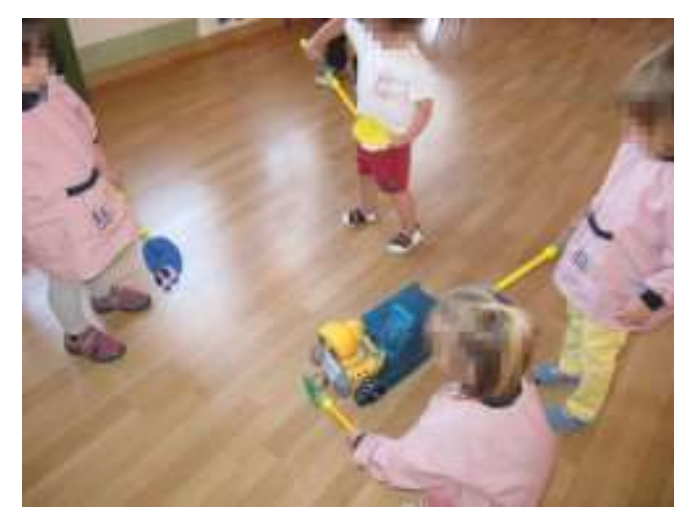

Figure 9. Children driving a mobile robot (extracted from [48]).

The use of robots is also being considered with commercial purposes. Recently, Fisher Price presented Code-a-Pillar ${ }^{2}$, a robotic caterpillar to teach programing to children aged from 3 to 8 years. Several segments can be attached to the motorized head of the caterpillar and each one works as an instruction to be executed sequentially. Each block has a functionality such as go forward, go back, turn left/right or stop and play a song (see Figure 10). As Fisher Price points out, the Code-a-Pillar robot is aimed to inspire logical thinking and foster problem solving skills in the youngest.

\footnotetext{
${ }^{2}$ http://www.fisher-price.com/en_US/codeapillar/index.html
} 


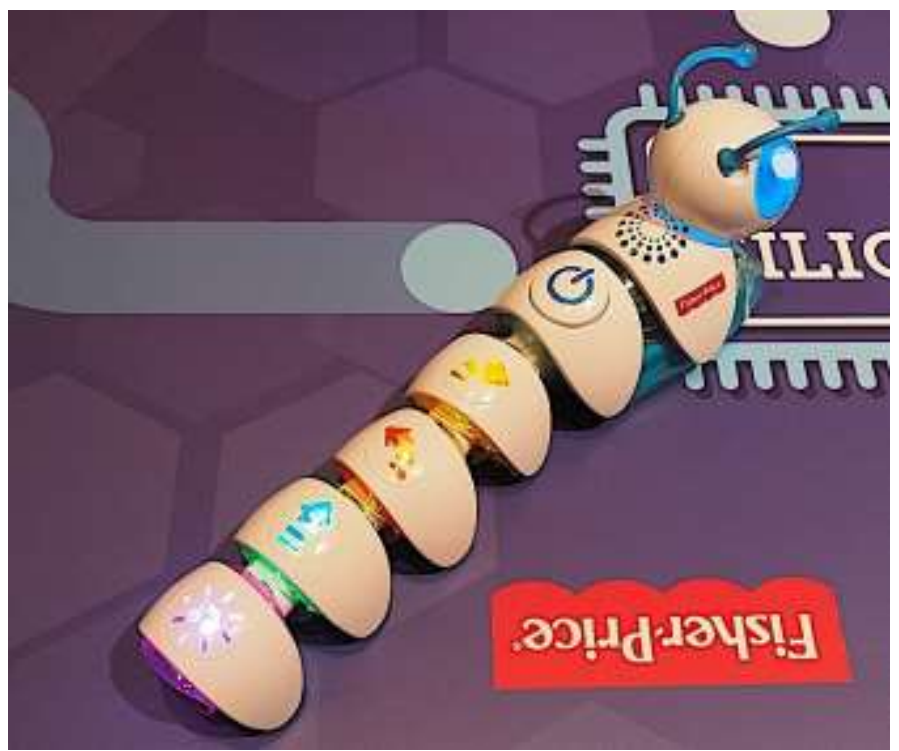

Figure 10. The Code-a-Pillar robot presented by Fisher-Price.

\subsection{Ubiquitous games}

Finally, the previous technologies may be used simultaneously for creating Ambient Intelligence (AmI) environments that monitor children and adapt the activities to them depending on their actions in a natural and undetectable way [49]. A first step was made by Steurer and Srivastava [50] who presented a smart table that automatically monitors kid's interaction (with tangible blocks) on the surface and enables educators to follow the children's learning progress. Another example in this direction is the work by Bobick et al. [51] with the KidsRoom which immerses children in a fantasy adventure in which children must cooperate together to explore a fantasy story. The story goes ahead when cooperative actions are made by children (e.g. rowing a virtual boat or yelling a magic word) and the actions are captured with cameras and microphones in the room (Figure 11).
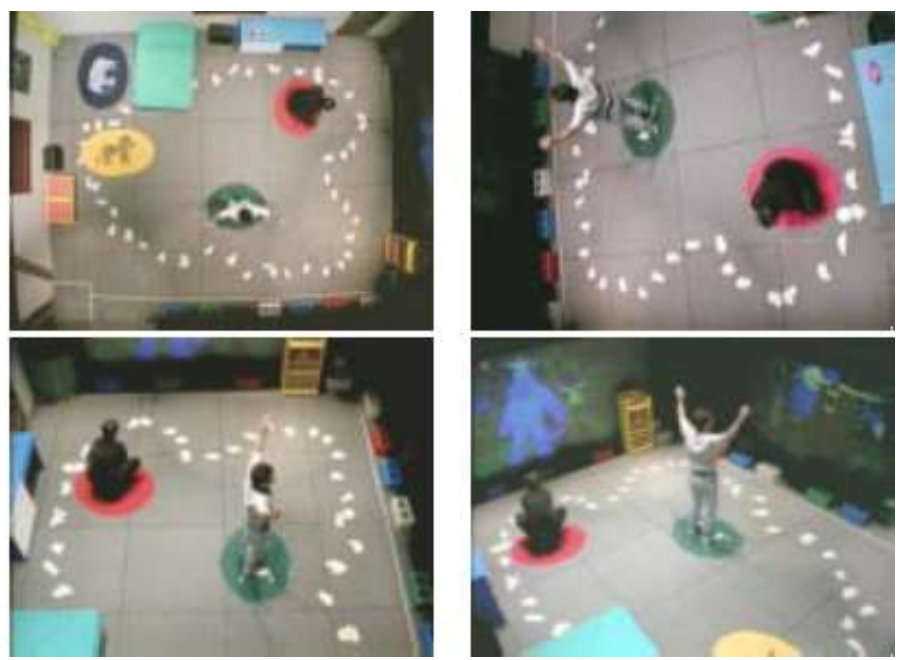

Figure 11. The Kidroom from the three cameras used to sensor (extracted from [51]). 
Another example is the work by Chen et al [52] who presented $\operatorname{SmartKG}$, a sensor-instrumented environment for early childhood education. The system uses unobtrusive sensors (microphones, video cameras and motion detectors) to continuously monitor the interactions between children, teachers and the objects located in the classroom. In addition, a sensor-instrumented badge has to be worn by children and teachers in order to provide to the system meaningful location information. The environment collects, interprets and presents the data in a user-friendly way for helping educators to widely explore the children learning process through both, their progress in the proposed activities and their social behavior. In the same line of providing children's information to teachers, Hwang et al [53] proposed a system to monitor children's behavior in out-of-classroom activities like field trips. In this case, children worn a backpack equipped with a sensor mote and a smartphone for sensing the data (see Figure 12). Moreover, the authors tried to include a camera in a cap in order to have accurate data about children's point of view but it was too obtrusive for children since a cap is not a regular clothing accessory for them.

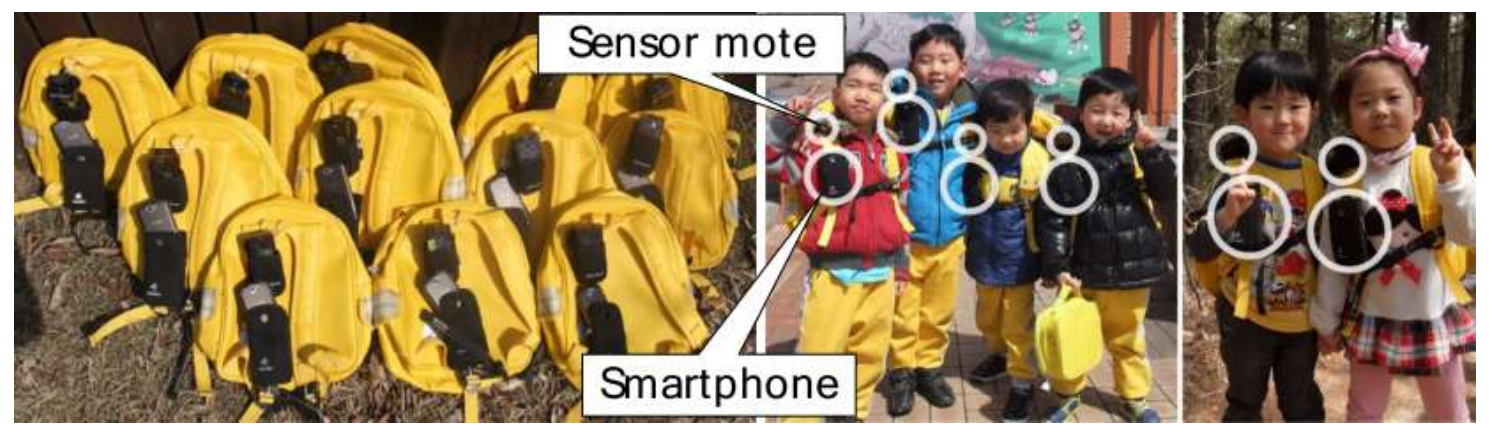

Figure 12. The backpack used for tracking in [53].

These systems are a step forward in the development of ambient intelligent environments but they are unable to adapt dynamically the characteristics of the learning/game environment by analyzing the context information obtained by the installed sensor infrastructure.

\section{Discussion}

In Table 1, the works listed above are classified in terms of several factors. On the one hand, the age of the users involved and the capacities, inferred from [54], that the proposed technologies can improve: physical development (P), socio-affective development (S) and cognitive and intellectual development (I). For each capacity there are several areas of improvement: related to physical development the analyzed works address physical exercise (P-p) and fine motor skills (P-f); in the social development we can identify the collaboration area (S-c); and in the cognitive and intellectual development we can find the areas that target spatial (I-s), linguistic (I-1), logic and mathematic (I-m), and the exploration and discovery (I-e) skills. The works are also categorized by the technology used, namely computers (C), tablets (T), mobiles/smartphones (M), tabletops (TT) or robots (R). And, finally, the last dimension covers 
the type or means of interaction: tangible (T), keyboard (K), mouse (Mo), joystick (J), multitouch $(\mathrm{M})$, body gestural $(\mathrm{G})$ or vocal $(\mathrm{V})$.

Table 1. Comparison of works

\begin{tabular}{|c|c|c|c|c|c|}
\hline Work & Age (years) & Capacities & Areas & Technology & Interaction \\
\hline [12] & $2-3$ & I & $\mathrm{I}-1, \mathrm{I}-\mathrm{m}$ & $\mathrm{C}$ & $\bar{K}$ \\
\hline [13] & $6-7$ & I & I-1 & $\mathrm{C}$ & Mo, K \\
\hline [15] & $4-5$ & $\mathrm{P}$ & P-f & $\mathrm{C}$ & Mo \\
\hline [14] & 3 & $\mathrm{P}$ & P-f & $\mathrm{C}$ & Mo, J, B \\
\hline [16] & $3-11$ & I & $\mathrm{I}-1$ & $\mathrm{C}$ & V \\
\hline [35] & $2-3$ & $\mathrm{P}$ & P-f & $\mathrm{T}$ & M \\
\hline [36] & $2-3$ & $\mathrm{P}$ & P-f & $\mathrm{T}$ & M \\
\hline [37] & $3-6$ & $\mathrm{P}$ & P-f & T-M & M \\
\hline$[38]$ & $2-3$ & $\mathrm{P}$ & P-f & $\mathrm{T}$ & M \\
\hline [39] & $2-3$ & I & I-1 & $\mathrm{T}$ & M \\
\hline [40] & $2-5$ & I & I-1 & $\mathrm{T}$ & M \\
\hline [32] & 4-6 & I & $\mathrm{I}-\mathrm{m}$ & $\mathrm{T}$ & M \\
\hline [33] & $3-7$ & I & $\mathrm{I}-1$ & $\mathrm{~T}$ & M \\
\hline [34] & $4-5$ & I, S & $\mathrm{I}-\mathrm{m}, \mathrm{S}-\mathrm{c}$ & $\mathrm{T}$ & M \\
\hline [23] & $5-6$ & I & I-1,I-s, I-m & TT & M \\
\hline [24] & $3-5$ & I & $\mathrm{I}-\mathrm{m}$ & TT & $\mathrm{T}$ \\
\hline [25] & $5-7$ & I, S & $\mathrm{I}-1, \mathrm{~S}-\mathrm{c}$ & TT & M \\
\hline [26] & $3-4$ & $\mathrm{~S}$ & S-c & TT & $\mathrm{T}$ \\
\hline [27] & $3-4$ & S & S-c & TT & $\mathrm{T}$ \\
\hline [19] & $4-6$ & I, P & $\mathrm{I}-, \mathrm{P}-\mathrm{p}$ & TT & M \\
\hline [20] & 4-6 & I & $\mathrm{I}-\mathrm{m}$ & $\mathrm{TT}$ & M \\
\hline [21] & $3-4$ & I & I-e, S-c & TT & M \\
\hline [22] & $4-6$ & I & I-s & M & M \\
\hline [42] & $3-6$ & I & I-1 & $\mathrm{R}$ & V, G \\
\hline [43] & $3-6$ & I & $\mathrm{I}-1$ & $\mathrm{R}$ & V, G \\
\hline [44] & $4-6$ & I & I-1 & $\mathrm{R}$ & G \\
\hline [45] & $4-6$ & I & $\mathrm{I}-1$ & $\mathrm{R}$ & $\mathrm{T}$ \\
\hline [46] & $3-6$ & I & I-s & $\mathrm{R}$ & $\mathrm{T}$ \\
\hline [47] & $0-2$ & $\mathrm{P}$ & P-p & $\mathrm{R}$ & $\mathrm{T}, \mathrm{G}$ \\
\hline [48] & $2-5$ & I, S & I-s, S-c & $\mathrm{R}$ & $\mathrm{T}$ \\
\hline
\end{tabular}

The previous review of works suggests that not all the technologies considered fit in the same way into the children's development and the requirements that the educational activities should fulfill. The use of traditional computers limits the creation of educational activities targeted to preschool children since they are placed in a fixed location and this prevents designers from developing activities that involve children's movement along the space where the activity is been carried out. Moreover, traditional computers use a mediated interaction (mouse and keyboard) which is not very natural or intuitive for this specific type of users who have not fully developed their fine motor skills yet. In addition, the use of these mono-user mediated 
interactions with a mouse and a keyboard obstruct collaborative activities with children. The use of tabletop technologies solves several limitations of the traditional computers. Firstly, the way in which users interact with the technology changes to a direct-touch approach (tangible or tactile interaction), which, as Hourcade points out [55], is preferred over mediated pointing devices by children. Secondly, the tabletop's form factor and size offers more opportunities for supporting collaboration between peers than the traditional computers do. In this respect, several works have evaluated the suitability of tabletops for supporting collaboration [56-58] and even for fostering creativity [59,60]. Regardless of these advantages, tabletops are also fixed to a location and are very expensive preventing the acquisition of large number of devices in education centers. Finally, the use of tablets and smartphones solves these two limitations. These devices allow the movement of children with the device along the area where the activity is being carried out. Besides, tablets have a much lower cost which makes them an affordable technology for most schools. Finally, looking at the year of publication of the works listed, there is a trend to leave the use of traditional computer and tabletop technologies behind and choose the tablets and smartphones for developing games for the youngest. Moreover, the works published in recent years also use robot technologies for developing educational games for preschoolers. Robots, as well as tablets and smartphones, can be moved (or move autonomously) around the space and foster children's movement and physical exercise. The interaction with robots is usually carried out by using tangible or gestural interaction overcoming the mediated interaction of traditional computers [61]. Additionally, robots gather several people around simultaneously and support collaborative and cooperative activities. Seeing that the most emergent technologies when designing educational games for the youngest are robots, tablets and smartphones, the multi-touch and tangible interactions seem the most promising techniques that will need further research efforts to analyze their adequacy and limitations when applied to this specific type of users.

In addition, this paper lists a set of works that addressed the design of a ubiquitous game. Some of these works are outdated and most of them are focused in monitoring children and provide their data to teachers and not to develop an environment that enriches children's activities through the use of technologies. Hence, new approaches are needed that take advantage of the newest technologies available to design ambient intelligent games that support children's development and satisfy children's expectations when playing. These new approaches should use the new technologies to augment the real space but not replace the natural and real-world activities which children are comfortable with. Moreover, these environments should provide fully engagement activities and immersion at the same time that support collaborative play and fosters creativity and imagination in children. According to the works reviewed above, these characteristics could be achieved with the technologies that have been discussed here and, in this respect; the current state of $\mathrm{HCI}$ is quite advanced to provide natural interactions. However, 
as Cook et al [62] pointed out, AmI environments should also sense users' actions and the state of the activity, reason about this information and, finally, make decisions and act accordingly to this information. In this respect, there remains a long way of research in the areas of sensing children movement and developing Artificial Intelligence algorithms that use this information for acting accordingly. These areas should be the focus of future research to enable the creation of AmI games targeted to the youngest.

On the other hand, regarding the dimensions of development that the reviewed works address, there are a great number of efforts put into the development of the physical and intellectual capacities of children. As for the physical capacities, most works present activities and games that could give support to the development of fine motor skills. However, in this dimension few works have been proposed with preschool children when developing games that support their gross motor skills or promote health and wellbeing through performing physical activity and active play. In our opinion, it will be interesting to develop games that support this type of development and we think that tablets, smartphones and robots are the best technological platforms for supporting the gross motor skills development since they have the ability to be moved from one place to another and, hence, allow children's movement. Regarding the cognitive and intellectual dimension, most works focus on developing games that foster the logic, mathematic and linguistic skills. Hence, there is a lack of works that develop games for giving support to the development of spatial abilities or games supporting creativity, exploration and discovery.

On the other hand, despite there are several works that point out the suitability of the new technologies, such as tabletops, tablets, smartphones and robots for collaborative playing, and children playing together can beat playing alone [63], the development of games that support social and affective skills in preschool children is not fully exploited. Hence, a future work to be addressed in the area is the use of these technologies for designing games that allow, support and foster cooperative and collaborative play. Finally, none of the works explored the areas in the social-affective dimension. Hence, future games targeting preschooler's development could focus on giving support to the development of self-awareness, self-regulation and emotional intelligence of children. These unexplored areas will have to be the focus of intense research in the near future to create games that support all the dimensions of preschool children's development identified.

\section{Conclusions}

Summing up, the contributions of this paper are manifold. First, a review of the current state of the art of technology-aided activities that support pre-kindergarten and kindergarten children's development in three dimensions (physical, socio-affective and cognitive) has been made. The analysis of the existent literature reveals that game technologies are suitable for supporting the 
improvement and development of very young children capacities. The second contribution is a set of future challenges that list the unexplored areas of preschool children's development in each technology in which game technologies may have a real and noticeable impact. These identified areas have to be the focus of intense research in the future to create games that support all the dimensions of preschool children's development effectively. Moreover, the most emergent technologies for developing educational games for prekindergarten and kindergarten children were identified. Finally, this work points out the need of future research combining technologies for giving support to Ambient Intelligence educational games that promote children's development.

\section{Acknowledgments}

This work received financial support from Spanish Ministry of Economy and Competitiveness and funded by the European Development Regional Fund (EDRF-FEDER) with the project TIN2014-60077-R (SUPEREMOS). This work is also supported by a pre-doctoral fellowship within the FPU program from the Spanish Ministry of Education, Culture and Sports to V. Nacher (FPU14/00136) and from GVA (ACIF/2014/214) to F. Garcia-Sanjuan.

\section{References}

[1] J. Huizinga, Homoludens, Wolters-Noordhoff, Groningen, 1985.

[2] G.G. Fein, Reviews Pretend Play in Childhood: An Integrative Review, Child Dev. 52 (1981) 1095-1118. doi:10.1111/1467-8624.ep8860387.

[3] D. Singer, R. Michnick, K. Hirsh-Pasek, Play Learning: How play motivates and enhances children's cognitive and social-emotional growth, Oxford University Press, USA, 2006.

[4] K.R. Ginsburg, The Importance of Play in Promoting Healthy Child Development and Maintaining Strong Parent-Child Bonds, Pediatrics. 119 (2007) 182-191. doi:10.1542/peds.2006-2697.

[5] D. Plato, The Republic, Penguin Books Ltd, 1955.

[6] L. Barnett, Developmental benefits of play for children, J. Leis. Res. 22 (1990) 138-153.

[7] I.P. Samuelsson, M.A. Carlsson, The Playing Learning Child: Towards a pedagogy of early childhood, Scand. J. Educ. Res. 52 (2008) 623-641. doi:10.1080/00313830802497265.

[8] L.M. Morrow, Preparing the classroom environment to promote literacy during play, Early Child. Res. Q. 5 (1990) 537-554. doi:10.1016/0885-2006(90)90018-V.

[9] J.L. Frost, S.C. Wortham, S. Reifel, Play and Child Development, Pearson, 2011. 
[10] J. Veitch, S. Bagley, K. Ball, J. Salmon, Where do children usually play? A qualitative study of parents' perceptions of influences on children's active free-play, Health Place. 12 (2006) 383-393. doi:10.1016/j.healthplace.2005.02.009.

[11] M.B. Parten, Social play among preschool children., J. Abnorm. Soc. Psychol. 28 (1933) 136-147. doi:10.1037/h0073939.

[12] M. Jones, M. Liu, Introducing Interactive Multimedia to Young Children: A Case Study of How Two-Year-Olds Interact with the Technology, J. Comput. Child. Educ. 8 (1997) 313-343.

[13] V. van Daal, P. Reitsma, Computer-assisted learning to read and spell: results from two pilot studies, J. Res. Read. 23 (2000) 181-193. doi:10.1111/1467-9817.00113.

[14] E.F. Strommen, G.L. Revelle, L.M. Medoff, S. Razavi, Slow and steady wins the race? Three-year-old children and pointing device use, Behav. Inf. Technol. 15 (1996) 57-64. doi:10.1083/jcb1666rr4.

[15] D. Ahlström, M. Hitz, Revisiting PointAssist and Studying Effects of Control- Display Gain on Pointing Performance by Four-Year-Olds, in: Proc. 12th Int. Conf. Interact. Des. Child., ACM, 2013: pp. 257-260. doi:10.1145/2485760.2485792.

[16] A.A. Navarro-Newball, D. Loaiza, C. Oviedo, A. Castillo, A. Portilla, D. Linares, et al., Talking to Teo: Video game supported speech therapy, Entertain. Comput. 5 (2014) 401-412. doi:10.1016/j.entcom.2014.10.005.

[17] S.P. Smith, E. Burd, J. Rick, Developing, evaluating and deploying multi-touch systems, Int. J. Hum. Comput. Stud. 70 (2012) 653-656. doi:10.1016/j.ijhes.2012.07.002.

[18] B. Shneiderman, C. Plaisant, M. Cohen, S. Jacobs, Designing the User Interface: Strategies for Effective Human-Computer Interaction, 5th ed., Prentice Hall, 2009.

[19] D. Kammer, R. Dang, J. Steinhauf, R. Groh, Investigating interaction with tabletops in kindergarten environments, in: Proc. 2014 Conf. Interact. Des. Child. - IDC '14, ACM Press, New York, New York, USA, 2014: pp. 57-66. doi:10.1145/2593968.2593975.

[20] K.S. Tyng, H.B. Zaman, A. Ahmad, Visual Application in Multi-touch Tabletop for Mathematics Learning: A Preliminary Study, in: 2nd Int. Conf. Vis. Informatics Sustain. Res. Innov., Springer, 2011: pp. 319-328.

[21] E.I. Mansor, A. De Angeli, O. de Bruijn, The fantasy table, in: 8th Int. Conf. Interact. Des. Child., ACM Press, New York, New York, USA, 2009: pp. 70-79. doi:10.1145/1551788.1551801.

[22] B. Huber, J. Tarasuik, M.N. Antoniou, C. Garrett, S.J. Bowe, J. Kaufman, Young children's transfer of learning from a touchscreen device, Comput. Human Behav. 56 (2016) 56-64. doi:10.1016/j.chb.2015.11.010.

[23] X. Yu, M. Zhang, J. Ren, H. Zhao, Z. Zhu, Experimental Development of Competitive Digital Educational Games on Multi-touch Screen for Young Children, in: 5th Int. Conf. E-Learning Games (Edutainment 2010), Springer, 2010: pp. 367-375. 
[24] M. Khandelwal, A. Mazalek, Teaching table: a tangible mentor for pre-k math education, in: Proc. 1st Int. Conf. Tangible Embed. Interact., ACM, New York, 2007: pp. 191-194. doi: $10.1145 / 1226969.1227009$.

[25] R.J.W. Sluis, I. Weevers, C.H.G.J. van Schijndel, L. Kolos-Mazuryk, S. Fitrianie, J.B.O.S. Martens, Read-It: Five-to-seven-year-old children learn to read in a tabletop environment, in: 2004 Conf. Interact. Des. Child. Build. a Community, ACM Press, New York, New York, USA, 2004: pp. 73-80. doi:10.1145/1017833.1017843.

[26] J. Marco, E. Cerezo, S. Baldasarri, E. Mazzone, J.C. Read, User-Oriented Design and Tangible Interaction for Kindergarten Children, in: 8th Int. Conf. Interact. Des. Child., ACM, 2009: pp. 190-193.

http://giga.cps.unizar.es/affectivelab/publications/short_IDC_2009.pdf.

[27] J. Marco, E. Cerezo, S. Baldassarri, Evaluating a Tangible Game Video Console for Kids, in: 12th IFIP TC 13 Int. Conf. Human-Computer Interact. (INTERACT 2009), Springer, 2009: pp. 141-144. doi:10.1007/978-3-642-03655-2_17.

[28] R. Rädle, H.-C. Jetter, N. Marquardt, H. Reiterer, Y. Rogers, HuddleLamp: SpatiallyAware Mobile Displays for Ad-hoc Around-the-Table Collaboration, in: Proc. Ninth ACM Int. Conf. Interact. Tabletops Surfaces - ITS '14, ACM Press, New York, New York, USA, 2014: pp. 45-54. doi:10.1145/2669485.2669500.

[29] F. Garcia-Sanjuan, J. Jaen, A. Catala, G. Fitzpatrick, Airsteroids: Re-designing the Arcade Game Using MarkAirs, in: Proc. 2015 Int. Conf. Interact. Tabletops Surfaces ITS '15, ACM Press, New York, New York, USA, 2015: pp. 413-416. doi:10.1145/2817721.2823480.

[30] L. Johnson, S. Adams, M. Cummins, The NMC Horizon Report: 2012 K-12, The New Media Consortium, Austin, Texas, 2012.

[31] K. Hirsh-Pasek, J.M. Zosh, R.M. Golinkoff, J.H. Gray, M.B. Robb, J. Kaufman, Putting Education in "Educational" Apps: Lessons From the Science of Learning, Psychol. Sci. Public Interes. 16 (2015) 3-34. doi:10.1177/1529100615569721.

[32] N. Zaranis, M. Kalogiannakis, S. Papadakis, Using Mobile Devices for Teaching Realistic Mathematics in Kindergarten Education, Creat. Educ. 04 (2013) 1-10. doi:10.4236/ce.2013.47A1001.

[33] C. Chiong, C. Shuler, Learning: Is there an app for that? Investigations of young children's usage and learning with mobile devices and apps, New York, 2010.

[34] J. Berggren, C. Hedler, CamQuest: Design and Evaluation of a Tablet Application for Educational Use in Preschools, in: Proc. 2014 Conf. Interact. Des. Child. - IDC '14, 2014: pp. 185-188. doi:10.1145/2593968.2610448.

[35] V. Nacher, J. Jaen, E. Navarro, A. Catala, P. González, Multi-touch gestures for prekindergarten children, Int. J. Hum. Comput. Stud. 73 (2015) 37-51. doi:10.1016/j.ijhes.2014.08.004.

[36] V. Nacher, J. Jaen, A. Catala, E. Navarro, P. Gonzalez, Improving Pre-Kindergarten Touch Performance, in: Proc. 9th ACM Int. Conf. Interact. Tabletops Surfaces, ACM, New York, 2014: pp. 163-166. doi:10.1145/2669485.2669498. 
[37] R. Vatavu, G. Cramariuc, D.M. Schipor, Touch interaction for children aged 3 to 6 years : Experimental fi ndings and relationship to motor skills, Int. J. Hum. Comput. Stud. 74 (2015) 54-76. doi:10.1016/j.ijhcs.2014.10.007.

[38] V. Nacher, J. Jaen, Evaluating the Accuracy of Pre-Kindergarten Children Multi-touch Interaction, in: IFIP TC.13 Int. Conf. Human-Computer Interact. - INTERACT, Bamberg, 2015.

[39] V. Nacher, J. Jaen, A. Catala, Exploring Visual Cues for Intuitive Communicability of Touch Gestures to Pre-kindergarten Children, in: Proc. Ninth ACM Int. Conf. Interact. Tabletops Surfaces - ITS '14, ACM Press, New York, New York, USA, 2014: pp. 159162. doi:10.1145/2669485.2669523.

[40] A. Hiniker, K. Sobel, S.R. Hong, H. Suh, I. Irish, D. Kim, et al., Touchscreen Prompts for Preschoolers: Designing Developmentally Appropriate Techniques for Teaching Young Children to Perform Gestures, Proc. 14th Int. Conf. Interact. Des. Child. (2015) 109-118. doi:10.1145/2771839.2771851.

[41] A. Strawhacker, M.U. Bers, "I want my robot to look for food": Comparing Kindergartner's programming comprehension using tangible, graphic, and hybrid user interfaces, Int. J. Technol. Des. Educ. (2014). doi:10.1007/s10798-014-9287-7.

[42] M. Ghosh, F. Tanaka, The impact of different competence levels of care-receiving robot on children, in: IEEE Int. Conf. Intell. Robot. Syst., IEEE, 2011: pp. 2409-2415. doi:10.1109/IROS.2011.6048743.

[43] F. Tanaka, S. Matsuzoe, Learning Verbs by Teaching a Care-Receiving Robot by Children: An Experimental Report, in: Proc. 7th Annu. ACM/IEEE Int. Conf. HumanRobot Interact., ACM, 2012: pp. 253-254. doi:10.1145/2157689.2157781.

[44] I. Soute, H. Nijmeijer, An Owl in the Classroom: Development of an Interactive Storytelling Application for Preschoolers, in: Proc. 2014 Conf. Interact. Des. Child., ACM, 2014: pp. 261-264. doi:10.1145/2593968.2610467.

[45] Y. Shen, Y. Qiu, K. Li, Y. Liu, Beelight: helping children discover colors, in: Proc. 12th Int. Conf. Interact. Des. Child., ACM, 2013: pp. 301-304. doi:10.1145/2485760.2485813.

[46] F. Tanaka, T. Takahashi, A tricycle-style teleoperational interface that remotely controls a robot for classroom children, in: Proc. 7th Annu. ACM/IEEE Int. Conf. Human-Robot Interact., 2012: pp. 255-256. doi:10.1145/2157689.2157782.

[47] F. Tanaka, B. Fortenberry, K. Aisaka, J.R. Movellan, Plans for Developing Real-time Dance Interaction between QRIO and Toddlers in a Classroom Environment, in: Procceedings 4th Int. Conf. Dev. Learn., IEEE, 2005: pp. 142-147. doi:10.1109/DEVLRN.2005.1490963.

[48] F. Garcia-Sanjuan, J. Jaen, V. Nacher, A. Catala, Design and Evaluation of a Tangible Mediated Robot for Kindergarten Instruction, in: 12th Int. Conf. Adv. Comput. Entertain. Technol., Iskandar, Malaysia, 2015.

[49] IST Advisory Group, Scenarios for ambient intelligence in 2010, 2001. 
[50] P. Steurer, M.B. Srivastava, System design of Smart Table, Proc. First IEEE Int. Conf. Pervasive Comput. Commun. (PerCom 2003). (2003) 473-480.

doi:10.1109/PERCOM.2003.1192772.

[51] A.F. Bobick, S.S. Intille, J.W. Davis, F. Baird, C.S. Pinhanez, L.W. Campbell, et al., The KidsRoom: A Perceptually-Based Interactive and Immersive Story Environment, Presence Teleoperators Virtual Environ. 8 (1999) 369-393.

doi:10.1162/105474699566297.

[52] a. Chen, R.R. Muntz, S. Yuen, I. Locher, S.I. Sung, M.B. Srivastava, A support infrastructure for the smart kindergarten, IEEE Pervasive Comput. 1 (2002) 49-57. doi:10.1109/MPRV.2002.1012337.

[53] I. Hwang, H. Jang, T. Park, A. Choi, Y. Lee, C. Hwang, et al., Leveraging children's behavioral distribution and singularities in new interactive environments: study in kindergarten field trips, Pervasive'12 Proc. 10th Int. Conf. Pervasive Comput. 7319 (2012) 39-56. doi:10.1007/978-3-642-31205-2.

[54] Jefatura del Estado, Ley Orgánica 2/2006, de 3 de mayo, de Educación., 2006. http://www.boe.es/boe/dias/2006/05/04/pdfs/A17158-17207.pdf.

[55] J.P. Hourcade, Interaction Design and Children, Found. Trends Human-Computer Interact. 1 (2007) 277-392. doi:10.1561/1100000006.

[56] R. Fleck, Y. Rogers, N. Yuill, P. Marshall, A. Carr, J. Rick, et al., Actions speak loudly with words, in: ACM Int. Conf. Interact. Tabletops Surfaces, ACM Press, New York, New York, USA, 2009: pp. 189-196. doi:10.1145/1731903.1731939.

[57] J. Rick, P. Francois, B. Fields, R. Fleck, N. Yuill, A. Carr, Lo-fi prototyping to design interactive-tabletop applications for children, in: 9th Int. Conf. Interact. Des. Child., ACM Press, New York, New York, USA, 2010: pp. 138-146.

doi:10.1145/1810543.1810559.

[58] J. Rick, A. Harris, P. Marshall, R. Fleck, N. Yuill, Y. Rogers, Children designing together on a multi-touch tabletop, in: 8th Int. Conf. Interact. Des. Child., ACM Press, New York, New York, USA, 2009: pp. 106-114. doi:10.1145/1551788.1551807.

[59] J. Helmes, X. Cao, S.E. Lindley, A. Sellen, Developing the story: Designing an Interactive Storytelling Application, in: ACM Int. Conf. Interact. Tabletops Surfaces, ACM Press, New York, New York, USA, 2009: pp. 49-52. doi:10.1145/1731903.1731913.

[60] A. Catala, J. Jaen, B. van Dijk, S. Jordà, Exploring tabletops as an effective tool to foster creativity traits, in: 6th Int. Conf. Tangible, Embed. Embodied Interact., ACM Press, New York, New York, USA, 2012: pp. 143-150. doi:10.1145/2148131.2148163.

[61] J. Han, M. Jo, S. Park, S. Kim, The educational use of home robots for children, in: Rom. 2005. IEEE Int. Work. Robot Hum. Interact. Commun. 2005., IEEE, 2005: pp. 378-383. doi:10.1109/ROMAN.2005.1513808.

[62] D.J. Cook, J.C. Augusto, V.R. Jakkula, Ambient intelligence: Technologies, applications, and opportunities, Pervasive Mob. Comput. 5 (2009) 277-298. doi:10.1016/j.pmcj.2009.04.001. 
[63] K. Inkpen, K.S. Booth, M. Klawe, R. Upitis, Playing together beats playing apart, especially for girls, in: First Int. Conf. Comput. Support Collab. Learn. - CSCL '95, Association for Computational Linguistics, Morristown, NJ, USA, 1995: pp. 177-181. doi: $10.3115 / 222020.222164$. 